\title{
PESTWEB: A WEED AND PEST INFORMATION SOURCE FOR FARMERS
}

\author{
K.N. TOZER ${ }^{1}$, C.M. FERGUSON ${ }^{2}$ and S. GLENNIE ${ }^{3}$ \\ ${ }^{I}$ AgResearch Ltd, Ruakura Research Centre, Hamilton, New Zealand \\ ${ }^{2}$ AgResearch Ltd, Invermay Agricultural Centre, Mosgiel, New Zealand \\ ${ }^{3}$ AbacusBio Limited, Dunedin, New Zealand
}

Corresponding author: katherine.tozer@agresearch.co.nz.

\begin{abstract}
Weed and insect pests severely limit New Zealand pasture production, and information on their management is often fragmented and difficult for farmers to access. While there are a number of good pest and weed websites available, many of these are commercial in focus or do not combine both identification and management options relevant to New Zealand farmers. PestWeb (www.agresearch.co.nz/pestweb) is a website being created to assist farmers and agricultural professionals in decision-making regarding weed and pest identification, biology, impact and management. A pilot site has been developed for identification and management of grass grub, porina, Californian thistle and barley grass, and it is aimed to include an additional 20-25 key New Zealand pasture weeds and pests, which will be chosen in consultation with key farming, industry and research personnel. This site will provide independent information in an easily accessible and intuitive format to assist farmers in weed and pest management decision-making. PestWeb development has involved collaboration between farmers of the South and West Otago Monitor Farm group, farming consultants, scientists and web designers. This has ensured that the site is 'farmer friendly', while providing independent, peer-reviewed information on the biology, control and impact of key pests and weeds.
\end{abstract}

\section{ESTABLISHMENT RATE OF 12 ORNAMENTAL GROUND COVER SPECIES FOR WEED CONTROL}

\section{C.L. FOO, K.C. HARRINGTON, M.B. MACKAY and M.P. WRIGLEY}

\author{
Institute of Natural Resources, Massey University, Private Bag 11-222, \\ Palmerston North 4442, New Zealand
}

Corresponding author: K.Harrington@massey.ac.nz

To determine how rapidly ornamental ground cover species can establish and thus potentially stop weeds from establishing, 12 perennial species with different growth forms and habits were planted into plots covered with $7 \mathrm{~cm}$ of sawdust mulch. Plants had a mean diameter varying from $10 \mathrm{~cm}$ to $41 \mathrm{~cm}$ when transplanted in November 2008 with $1.0 \mathrm{~m}$ spacing, with three plants per plot and three plots for each species. After 5 months, Polygonum capitatum had established the most rapidly, completely covering the plots in dense growth and seeding prolifically, but then it suffered a sudden die-back, apparently from frost damage. Ajuga reptans 'Caitlin's Giant' produced the tallest and densest cover within the first 5 months, with an average patch diameter of $83 \mathrm{~cm}$. Two other species exhibiting rapid establishment ability were Grevillea lanigera 'Little Drummer Boy' and Acaena inermis 'Purpurea'. The remaining species were slower to establish but several were beginning to also produce good weed-smothering ground covers. Sedum mexicana 'Acapulco Gold' produced dense patches once established but was the species most prone to being damaged by rabbits. Results obtained will facilitate selection of the most useful ground cover species for urban weed management. 